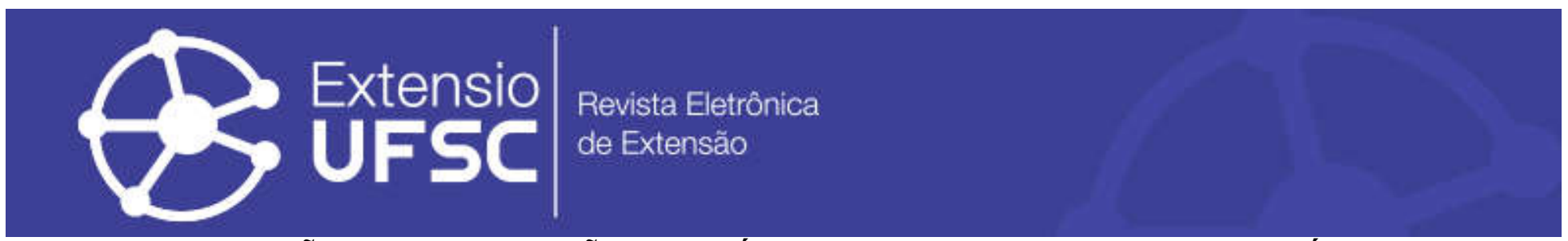

\title{
AÇÕES DE PROMOÇÃO DA SAÚDE COM A EQUIPE DO CONSULTÓRIO NA RUA DE FLORIANÓPOLIS
}

\author{
Cristine Moraes Roos \\ Universidade Federal de Santa Catarina \\ cristine.roos@ufsc.br \\ Milena Amorim Zuchetto \\ Universidade Federal de Santa Catarina \\ milenazuchetto3@gmail.com \\ André Felipe Britto de Mesquita \\ Universidade Federal de Santa Catarina \\ andrefbmesquita@gmail.com
}

\section{Resumo}

Objetiva-se promover ações de cuidado e saúde às pessoas em situação de rua através da parceria com a equipe do Consultório na Rua. As atividades são realizadas in loco, compartilhadas e integradas às Unidades Básicas de Saúde e com as equipes dos Centros de Atenção Psicossocial, serviços de Urgência e Emergência e outros serviços, de acordo com as necessidades do usuário. O processo de coleta de dados ocorreu em oito etapas, desde o princípio do projeto até os dias atuais. Este projeto de extensão tem sido desenvolvido entre março de 2018 até o presente momento. Consideramos fundamental ao aluno esta vivência, cujo interesse visa aprimorar o trabalho e a sua formação na graduação em enfermagem, tendo como perspectiva a qualificação da atenção e a inserção das necessidades dos sujeitos como fonte de produção de conhecimento e pesquisa nas instituições de ensino superior em consonância com o SUS.

Palavras-chaves: Extensão Universitária. Enfermagem. Consultório na Rua. Promoção da Saúde. Reabilitação Psicossocial.

\section{HEALTH PROMOTION ACTIONS WITH THE STREET CLINIC TEAM OF FLORIANÓPOLIS}

Abstract

The objective is to promote care and health actions to homeless persons through the partnership with the street clinic team. The activities are carried out in loco, shared and integrated to the Basic Health Units and with the teams of the Psychosocial Care Centers, Urgency and Emergency services and other services, according to the user's needs. The data collection process happened in eight stages, since the beginning of the project to the present day. This extension project has been developed from March of 2018 to the present. We consider this experience fundamental to the student, whose interest aims to improve the work and their training in undergraduate nursing, with the perspective of qualifying attention and inserting the needs of the subjects as a source of knowledge production and research in higher education institutions in line with the SUS.

Keywords: University Extension. Nursing. Street Clinic. Health Promotion. Psychosocial Rehabilitation.

\section{ACCIONES DE PROMOCIÓN DE LA SALUD CON EL EQUIPO DE CONSULTORÍA EN LA CALLE FLORIANÓPOLIS}

\section{Resumen}

El objetivo es promover acciones de atención y salud para las personas que viven en la calle a través de una alianza con el equipo de Consultório na Rua. Las actividades se realizan in loco, compartidas e integradas a las Unidades Básicas de Salud y con los equipos de los Centros de Atención Psicosocial, Servicios de Urgencias y Emergencias y otros servicios, de acuerdo a las necesidades del usuario. El proceso de recolección de datos se desarrolló en ocho etapas, desde el inicio del proyecto hasta la actualidad. Este proyecto de ampliación se ha desarrollado desde marzo de 2018 hasta la actualidad. Consideramos esta experiencia fundamental para el estudiante, cuyo interés apunta a mejorar el trabajo y su formación en la carrera de enfermería de pregrado, con la perspectiva de calificar la atención e insertar las necesidades de los sujetos como fuente de producción de conocimiento e investigación en las instituciones de educación superior en en línea con el SUS.

Palavras clave: Extensión Universitaria. Enfermería. Clínica de Calle. Promoción de la Salud. Rehabilitación Psicosocial. 
Ações de promoção da saúde com a equipe do consultório na rua de Florianópolis

\section{INTRODUÇÃO}

Compreende-se o surgimento da População em Situação de Rua (PSR) como fruto de processos de segregação social, que afeta um grupo de indivíduos que não tem condições de adaptar-se ao modelo econômico em vigor. Todavia, sabe-se que o preconceito e a exclusão deste grupo geram a marginalização e a indiferença com esses indivíduos, que são, de forma comum, evitados e invisíveis aos olhos da sociedade, deparando-se com a negação de seus direitos enquanto cidadãos (GOMES; SOUZA; LOPES, 2019).

A PSR caracteriza-se por um grupo heterogêneo de pessoas que compartilham de condições de vida semelhantes: o estado de extrema pobreza, a ruptura de vínculos familiares, e a falta de moradia fixa, e que acabam por utilizar os espaços públicos e as unidades de acolhimento para abrigo e sustento, seja de modo provisório ou permanente (BRASIL, 2012).

Diante disso, destaca-se que este grupo social está exposto a um conjunto de fatores que o tornam altamente vulneráveis, ao passo que apresenta-se em situação de precarização das condições de vida e de saúde, devido a fatores como violência, falta de fonte de renda, negligência de direitos humanos e sociais (VAN WIJK; MÂNGIA, 2019).

Devido à precariedade das condições de vida na rua, o estudo de Zandomingo et al. (2020) aponta que a PSR encontra-se mais suscetível a desenvolver lesões e problemas de saúde. Esses problemas sofrem influência de questões como: a baixa nutrição, devido à alimentação escassa; exposição a alterações climáticas; falta de água potável; prejuízo de sono e de afeição. Além de tudo, outros elementos que podem acrescentar vulnerabilidade ao viver da PSR são transtornos mentais, o uso de álcool ou outras drogas, sendo necessária a atenção integral da pessoa implicada em tal realidade.

Em consonância com Machado e Rabello (2018), ao que diz respeito às políticas públicas para PSR no Brasil, houve um incentivo legislativo para promover a ampliação ao acesso de direitos por meio da instituição da Política Nacional para a População em Situação de Rua (PNPR). Outra medida legal instituída foi a Política Nacional de Atenção Básica (PNAB), a qual criou a equipe de Consultório na Rua (eCR), visando oferecer assistência integral a essa população. A eCR é formada por múltiplos profissionais que prestam cuidado integral à PSR, no contexto da atenção primária, seja em Centros de Saúde (CS), seja na rua ou em unidades móveis de forma itinerante.

Isto posto, os Consultórios na Rua (CnaR) foram instituídos pela PNAB, buscando atuar diante dos diferentes problemas e necessidades de saúde dessa população, articulando-se com os 
Ações de promoção da saúde com a equipe do consultório na rua de Florianópolis

demais níveis de atenção, como, por exemplo, os Centros de Atenção Psicossocial (CAPS) e serviços de Urgência e Emergência (BRASIL, 2012).

Nesse sentido, é evidente que as ações de promoção e educação em saúde são fundamentais para a transformação de um comportamento negligenciado para uma atitude de protagonismo, impactando na vida de indivíduos em condições de vulnerabilidade. Logo, a consolidação de políticas públicas promove o empoderamento da PSR para o seu autocuidado, e autogestão através de informações e do conhecimento de seus direitos (SILVA; PRADO; RODRIGUES, 2020).

A atuação perante a PSR baseia-se em um trabalho incessante, no qual busca-se exatamente promover a visibilidade e a inclusão social dessas pessoas através da identificação das suas vulnerabilidades e fragilidades, bem como das suas potencialidades, para que assim seja possível o resgate social. Nessa ótica, os profissionais e pesquisadores têm o papel de pensar na construção de caminhos de transformação, em um horizonte voltado para a valorização da vida e da cidadania, objetivando a ampliação de novos dispositivos de cuidado, e para além disso, a oferta de atenção e cuidados integrais a essa população (MATOSO et al. , 2019).

Nessa perspectiva, o projeto de extensão intitulado "Ações de cuidado e promoção da saúde com a equipe do consultório na rua do município de Florianópolis - Santa Catarina" tem por finalidade desenvolver ações de cuidado e promoção da saúde, em parceria com a unidade móvel do CnaR do município de Florianópolis destinadas às PSR e vulnerabilidade social, usuárias ou não de substâncias psicoativas. Criou-se esse projeto em 2018, e desde então a iniciativa desenvolve-se a partir das atividades efetuadas pelos bolsistas de graduação em Enfermagem, sob orientação de uma professora coordenadora, sendo o projeto vinculado ao Laboratório de Ensino, Pesquisa, Extensão e Tecnologia em Enfermagem, Saúde e Reabilitação (Re)Habilitar da Universidade Federal de Santa Catarina (UFSC).

O projeto de extensão dar-se-á através da participação de acadêmicos nos cenários da comunidade em que o CnaR desenvolve suas ações de saúde. A evolução prática e científica do aluno ocorre a partir da obtenção de informações, impressões, sentimentos e observações do território (diário de campo), assim como a partir de atravessamentos teóricos da literatura e normas legislativas que protegem essa população.

Sabe-se que a participação acadêmica e a superação dos muros da universidade são ferramentas de mobilização política e social, beneficiando as ações realizadas em parceria com a equipe do CnaR no sentido de atualizações e trocas de conhecimento, bem como apoiando a PSR e trazendo à tona a relevância da temática em formato de produção científica. Somado a isso, o 
Ações de promoção da saúde com a equipe do consultório na rua de Florianópolis

Instituto de Pesquisa Econômica Aplicada (IPEA, 2020) revelou que a PSR brasileira cresceu 140\% desde 2012, alcançando o número de 222.000 brasileiros em março de 2020. Essa estatística tende a aumentar devido ao atual cenário de pandemia por Sars-Cov-2 (Covid-19), o qual coloca a economia e demais setores em grave crise.

Com isso, o presente estudo tem por finalidade relatar as experiências de acadêmicos de Enfermagem e descrever as ações de cuidado e promoção da saúde desenvolvidas com a eCR de Florianópolis, entre os períodos de 2018 a 2020, bem como demonstrar o impacto dessas ações extensionistas para a formação estudantil.

\section{MATERIAL E MÉTODOS}

Trata-se de um relato de experiência sobre o caráter das atividades extensionistas realizadas em parceria com a equipe do CnaR do município de Florianópolis. Nesse município foi instituído, pelo Ministério da Saúde, o programa de atenção à PSR, o qual possui como referência em nível de atenção primária o Centro de Saúde da Prainha, localizado em território adjacente ao centro da cidade. O CnaR se constitui num dispositivo de saúde que é composto por uma equipe multiprofissional itinerante que visa a atenção integral à PSR.

Essa integração com o componente da Rede de Atenção Psicossocial (RAPS) possibilita a busca ativa e o cuidado com os usuários de álcool, crack e outras drogas, além de fornecer um olhar multiprofissional dos diferentes problemas e necessidades dessa população (BRASIL, 2012). As atividades desenvolvidas por essa equipe ocorrem in loco, através de uma estratégia preventiva e de cuidado que permite a redução dos danos potenciais do uso de substâncias psicoativas, e o respeito às diversidades e direitos humanos.

O consultório móvel consiste em um reboque automotivo guiado por um carro da Secretaria de Saúde do município, o qual apresenta em seu interior uma mesa e bancos fixos, espaço para mobilização, pia para lavagem das mãos, balcão para preparo de procedimentos e armário fechado para armazenar recursos materiais e medicamentos. A finalidade desse consultório, em apresentar essa configuração, é pautada na essência de se aproximar da realidade das PSR, garantir o atendimento e acesso à rede intersetorial.

Cada município que possui esse programa de consultório móvel estabelece locais onde serão desenvolvidas as atividades. No caso de Florianópolis, por se tratar de um município de extensão importante, foram planejados quatro locais para atender às necessidades de saúde conforme determinação dos próprios profissionais responsáveis pelo serviço. Essa delimitação 
Ações de promoção da saúde com a equipe do consultório na rua de Florianópolis

apresenta-se da seguinte forma: na Praça Pedro Silvério, do bairro Lagoa da Conceição - Leste; na Praça Nossa Senhora de Fátima, do bairro Estreito - Continente; no estacionamento do posto de Polícia Militar, do município do bairro de Canasvieiras - Norte; e na Praça Fernando Machado, no bairro centro - Centro. Essa configuração geográfica é mais bem exemplificada na Figura 1.

Figura 1: Distribuição geográfica dos pontos de atendimento do consultório móvel à população em situação de rua no município de Florianópolis.

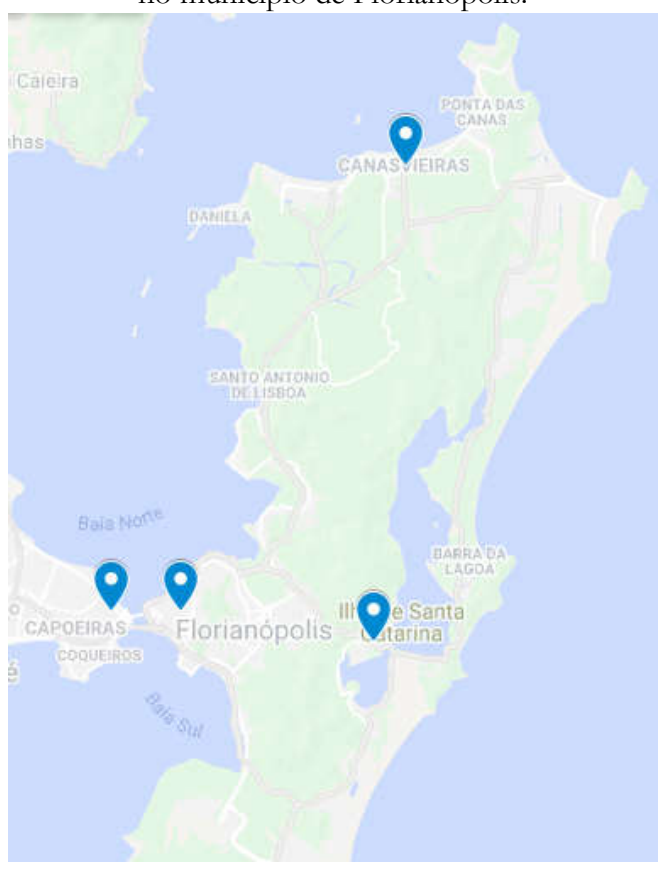

Fonte: Autores.

A amostra populacional incluída na pesquisa envolve: a equipe de saúde do CnaR, composta por 01 médica, 02 enfermeiras, 01 psicóloga, 02 Técnicas de Enfermagem, 01 Assistente Social; 01 motorista vinculado à Secretaria de Saúde do município; 06 alunos de graduação em Enfermagem com vínculo de bolsista de extensão pelo grupo (Re)Habilitar; 01 aluno de graduação em Psicologia; 01 residente de Medicina em Saúde da Família; 02 alunos de graduação em Enfermagem voluntários; 02 alunas de pós-graduação em Enfermagem (mestrado e doutorado) voluntárias; 01 professora coordenadora do projeto vinculada à UFSC; e PSR. O presente relato levará em conta os depoimentos dos seis alunos de graduação em Enfermagem com vínculo de bolsista de extensão pelo grupo (Re)Habilitar, os quais desenvolveram as atividades extensionistas do projeto vigente, bem como as perspectivas da professora coordenadora do projeto. 
Ações de promoção da saúde com a equipe do consultório na rua de Florianópolis

Esse projeto teve início no dia primeiro de março de 2018 e tem suas ações extensionistas ocorrendo até os dias de hoje. Vale ressaltar que, diante da situação de pandemia, as atividades presenciais cessaram, temporariamente, a partir de março de 2020, mas, por outro lado, foram desenvolvidas atividades virtuais para sensibilizar e discutir a temática da PSR através das mídias digitais do grupo de pesquisa.

O processo de coleta de dados ocorreu em oito etapas, desde o princípio do projeto até os dias atuais. A primeira etapa do projeto envolveu a aproximação do grupo de pesquisa ao contexto da equipe de CnaR do município de Florianópolis. A partir disso, o segundo momento da pesquisa consistiu na apresentação do projeto de extensão aos profissionais e delineamento de acordos para o desenvolvimento acadêmico no campo de ação. No terceiro momento da pesquisa ocorreu a imersão do coordenador e discentes no consultório móvel semanalmente, todas as terças-feiras, no período vespertino, conforme acordo inicial e cronograma de itinerário. A partir da imersão, na quarta etapa do projeto, foram desenvolvidas ações de cuidado à saúde de PSR no consultório móvel, colaborando com a equipe de saúde local e rede de atenção ampliada. No decorrer das atividades, os discentes registraram suas observações e experiências em formato de relatório, diário de campo, poema e registros fotográficos. Vale ressaltar que a terceira, quarta e quinta etapa foram desenvolvidas concomitantemente. O sexto momento do projeto envolveu a exposição de materiais, fotos e relatos para a comunidade acadêmica. A partir do sétimo momento, há o pano de fundo da pandemia como dificultador das atividades presenciais, isto posto, foram desenvolvidos artes e textos para divulgação da temática nas mídias digitais do grupo (Re)Habilitar. Por último, hoje o projeto encontra-se na oitava etapa de manutenção do material digital divulgado e aprofundamento teórico.

Em parceria com a equipe do consultório da rua, os acadêmicos realizaram diversas atividades ao longo do tempo do projeto. Os estudantes fizeram: a busca ativa dos usuários pelo território nos bairros mencionados; a promoção da saúde pela comunicação com as pessoas contactadas; oficinas de higiene e cuidados com a pele; biblioteca itinerante; confecção de materiais de divulgação nos meios digitais sobre as PSR; e a publicação de materiais científicos. Acerca dos aspectos éticos em pesquisa e ações extensionistas, o presente artigo faz parte do macroprojeto intitulado "Ações de cuidado e promoção da saúde com a equipe do consultório na rua do município de Florianópolis - Santa Catarina”, vinculado à Pró-Reitoria de Extensão (PROEX) da UFSC. 
Ações de promoção da saúde com a equipe do consultório na rua de Florianópolis

\section{RESULTADOS E ANÁLISE}

Acerca dos dados de caracterização da amostra de participantes da pesquisa, constatou-se que a maioria dos discentes era do gênero feminino (83,3\%), com faixa etária entre 23 e 30 anos (Média: 24,5 anos), em sua totalidade brancos e solteiros, com tempo de permanência no projeto de pesquisa oscilando entre um e 12 meses. Dentre os seis alunos incluídos na pesquisa, houve uma diversidade acerca da fase da graduação em que se encontravam durante o exercício da ação extensionista, variando entre o segundo e o sétimo período letivo. Ainda sobre a caracterização da amostra, dois discentes apresentavam ingresso anterior à outra graduação, ao passo que os demais experenciavam a primeira graduação. Ademais, todos os bolsistas possuíam naturalidade brasileira, de procedência dos estados do Paraná, Amazonas e Santa Catarina, residindo, no momento da participação, na região da Grande Florianópolis. A coordenadora do projeto é docente do Departamento de Enfermagem desde 2016, possui 38 anos, feminina, brasileira e natural do Rio Grande do Sul, residindo atualmente em Florianópolis.

Conforme o exposto no item Materiais e Métodos, o processo de coleta de dados foi separado em oito momentos. Aqui no item Resultados, os achados serão descritos da mesma maneira, visando uma exposição didática e cronológica de cada experiência. Anteriormente à coleta de dados em si, entre os meses de março e junho de 2018, ocorreu a aprovação do projeto pela Prefeitura Municipal e Escola de Saúde Pública de Santa Catarina, seleção do bolsista e instrução dele acerca do projeto. Logo, o primeiro momento é marcado pela aproximação do grupo de pesquisa (Re)Habilitar da UFSC com a realidade da equipe que exercia as atividades no consultório móvel. Foi agendado um encontro no mês de junho de 2018 para a exposição da propositiva do projeto, intenções e abordagens. Essa reunião ocorreu no auditório do Centro de Saúde do bairro Prainha e estavam presentes a graduanda bolsista, a professora coordenadora, a pós-graduanda voluntária ao projeto e membros da equipe de saúde de referência.

“(...) espera-se que os estudantes possam, a partir da experiência proposta, observar exemplos de sucesso no acesso a serviços de saúde pela população em situação de rua, através do vínculo estabelecido entre os usuários e a equipe interdisciplinar do Consultório na Rua, abordando estratégias para promoção e cuidados de saúde, bem como o acesso à saúde às pessoas em situação de rua, visando superar a invisibilidade e vulnerabilidades deste contingente populacional." (Notas de Campo Discente 01) 
Ações de promoção da saúde com a equipe do consultório na rua de Florianópolis

Após as explanações sobre a estrutura do projeto de pesquisa extensionista, os profissionais da equipe de saúde sanaram dúvidas acerca da exequibilidade da proposta e alinharam acordos passíveis conforme a realidade do cenário. Nessa reunião os profissionais apresentaram o cronograma de atividades semanal que anunciava onde a unidade móvel estaria locada. Com base na demanda e quantidade de usuários a serem atendidos, a equipe desloca-se para os locais de maior público na ilha, sendo esses: Centro, Estreito, Canasvieiras e Lagoa da Conceição. Nessa conversa, inclusive, a equipe salientou que há uma fragilidade do sistema quanto à disponibilidade do meio de locomoção e manutenção da unidade móvel.

Durante a reunião com a eCR, a acadêmica e coordenadora foram convidadas a participar de outra reunião com a Câmara dos Vereadores, a qual ocorrera no dia 29 do mesmo mês na perspectiva de discutir sobre as violações higienistas e criminalizadoras referentes às PSR. Essa reunião ampliada pretendeu abordar temas relacionados aos movimentos sociais, direito à cidade e à cidadania, de forma a proteger os homens e mulheres que resistem nas ruas do município.

"o assistente social do Centro POP deu um exemplo para mostrar que a presença da polícia em determinadas situações não estabelece um bom vínculo, e nos fez refletir. Se tivéssemos um problema com um vizinho na comunidade em que moramos e, antes de qualquer tentativa, levássemos a polícia junto para resolvê-lo, será que esse vínculo se iniciaria bem ou mal construído?” (Notas de Campo - Discente 01)

A partir do dia 10 de julho de 2018, iniciaram as atividades da bolsista junto com a eCR no bairro Estreito. A imersão da aluna aconteceu, principalmente, através da observação das ações em saúde dos profissionais, questionamento sobre os processos de trabalho e encaminhamentos. Foram muitas as descobertas e redescobertas que permearam o cuidado à PSR. Para a segurança da acadêmica, permanecia no campo um representante do grupo com graduação completa, de forma voluntária, fomentando o diálogo e troca de experiências.

"O trailer não tem maca rígida, portanto, não se realiza exame ginecológico, a estrutura serve para testes rápidos, aferição de pressão, medição de glicemia, disponibilização de preservativos e demais orientações. Além disso, a unidade recebe os pacientes do bairro que a equipe já acompanha, os quais são buscados pelo motorista da equipe, uma técnica de enfermagem e uma assistente social". (Notas de Campo Discente 01) 


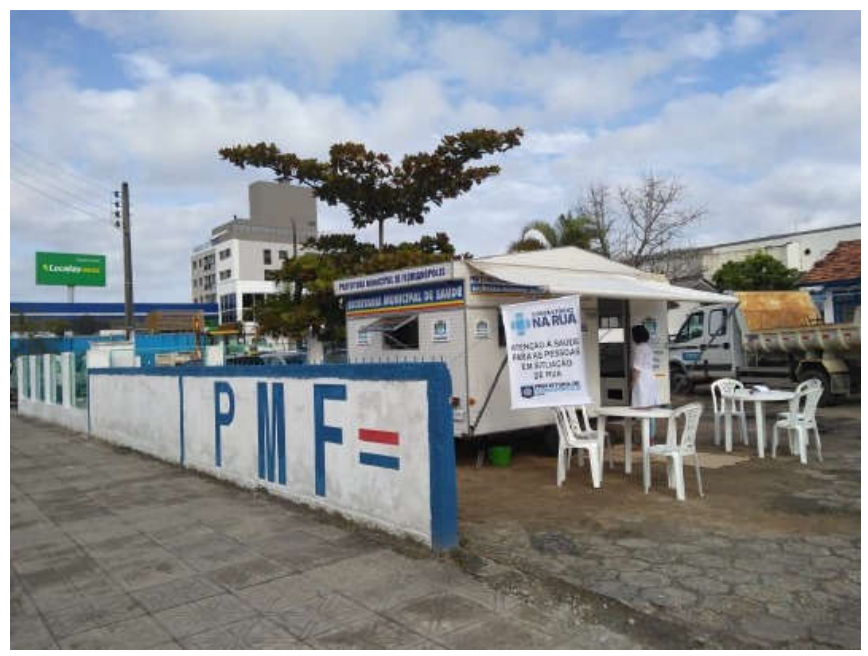

Figura 1: Consultório móvel de saúde para pessoas em situação de rua com cadeiras para atendimento externo do município de Florianópolis.

Com o passar do tempo, a aluna e a coordenadora do projeto foram se vinculando mais fortemente aos profissionais, encontrando demandas sociais e preocupações de saúde pública que poderiam ser transformadas. Dessa forma, a bolsista, com apoio de voluntários do grupo e equipe de saúde, realizou oficinas de corte de cabelo, acompanhamento de consultas de enfermagem e médicas, busca ativa dos usuários, escuta sensível aos problemas de saúde, bem como orientações de promoção de bem-estar. Além da criação de vínculo com a equipe que proporcionou convites para reuniões quinzenais de capacitação multiprofissional para a atenção da PSR.

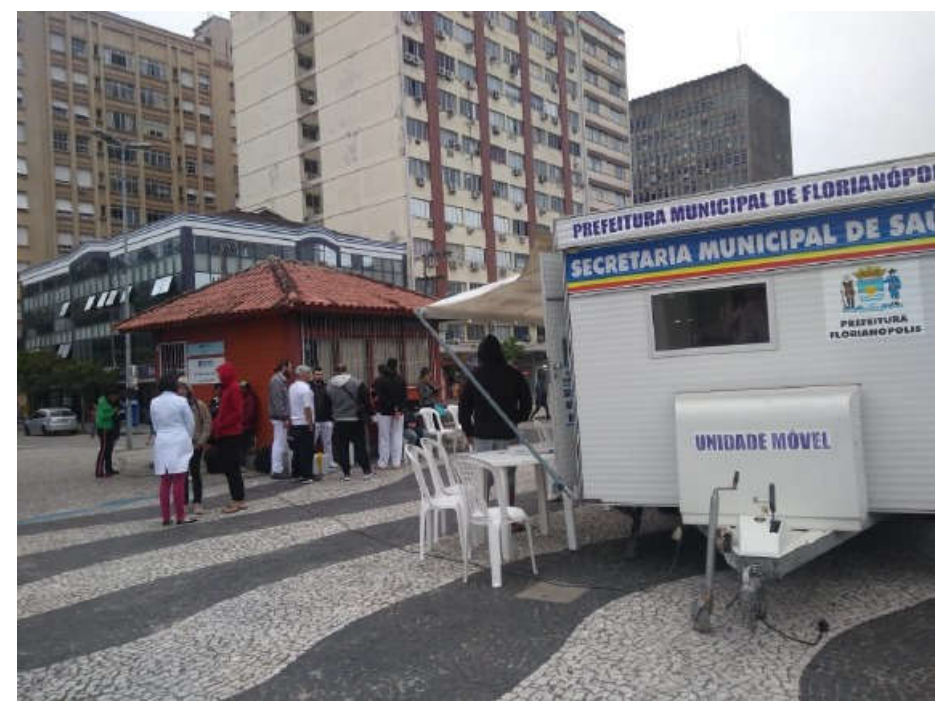

Figura 2: Oficina de corte de cabelo juntamente com a equipe de consultório na rua no Centro de Florianópolis. 


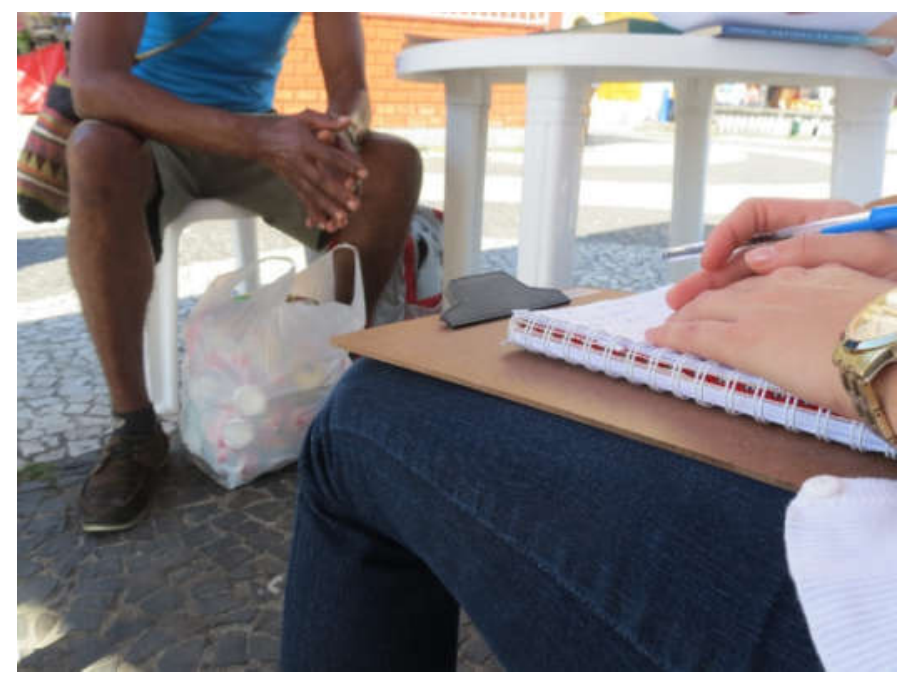

Figura 3: Conversa do profissional de saúde com uma pessoa em situação de rua.

A partir dessas ações voltadas à saúde da PSR e apoio da eCR, os bolsistas que experimentaram a experiência presencial no campo desenvolveram relatórios escritos em formato de notas de campo, diários de reflexões, elaboração de um poema e registros fotográficos. Essas observ(ações) apreendidas pelos alunos foram essenciais para a sensibilização dos mesmos sobre a temática, sendo necessário a fundamentação teórica para a prática clínica, mas também a reflexão sobre o viver na situação de rua. Para muitos alunos, a situação de rua era algo invisível e longe dos muros da universidade, entretanto, após essa aproximação, a temática tornou-se imprescindível para a formação profissional.

"Várias palavras me fizeram refletir sobre cada relato recebido hoje: descaso, descrédito, falta de acesso, invisibilidade, ignorância, falta de esperança. Contudo, o que mais ficou claro foi que mesmo muitas vezes os mesmos querendo estar naquela situação, ou mesmo não tiveram outra alternativa, não representa que eles não queiram e não necessitem de cuidado, de palavras, de escuta e de o mínimo de condições de acesso a um banho, alimentação e um abrigo que o proteja da chuva, do vento e da falta de humanidade de alguns seres da mesma espécie." (Trecho de poema - Discente 02).

Inclusive as experiências obtidas e registradas no decorrer das atividades de extensão foram expostas em diversos formatos, entre eles: rodas de conversa no grupo de pesquisa sobre demandas e políticas públicas que sustentam a atenção à saúde da PSR; exposição de fotos com murais físicos no hall do Centro de Ciências da Saúde, com espaço para diálogo entre acadêmicos de graduação sobre as experiências vivenciadas; trabalho de conclusão de curso de graduação em 
Ações de promoção da saúde com a equipe do consultório na rua de Florianópolis

Enfermagem intitulado "Pessoas em situação de rua sob a ótica da produção científica da enfermagem brasileira: Uma revisão integrativa", concluído em 2017; trabalho de conclusão de curso de graduação em Enfermagem intitulado "Aspectos sociais e clínicos associados à prevalência da reinfecção da tuberculose em um hospital de referência no Sul do Brasil”, em andamento; publicação de um capítulo de livro através do Programa de Atualização em Enfermagem da Associação Brasileira de Enfermagem (PROENF), intitulado "Reabilitação Psicossocial de Pessoas em Situação de Rua: atuação da Equipe de Atenção Primária à Saúde"; apresentação de resumos sobre o projeto de extensão no $71^{\circ}$ Congresso Brasileiro de Enfermagem em Manaus (Brasil) no ano de 2019 e no Congresso Internacional de Enfermagem de Reabilitação em Évora (Portugal), no ano de 2018; publicação do artigo científico intitulado "Locais de atenção à saúde das pessoas em situação de rua: construção de um mapa", no periódico denominado Brazilian Journal of Development, no ano de 2020; envio e aprovação de publicação de poesia intitulada "Vida na rua", pela Biblioteca Universitária no projeto "Histórias do cotidiano", em 2020.

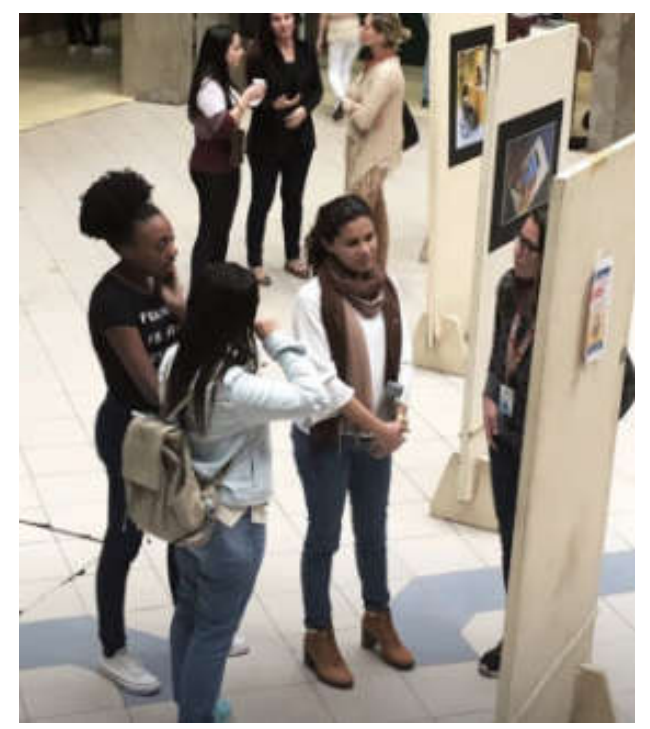

Figura 4: Exposição de fotografias das atividades executadas com a equipe de consultório de rua no hall do Centro de Ciências da Saúde.

A partir de meados de março de 2020, as atividades extensionistas presenciais foram interrompidas em virtude do cenário atual de pandemia por Covid-19. As atividades da eCR de Florianópolis foram suspensas e, desta forma, foi necessário repensar o formato do projeto em função do distanciamento social e isolamento domiciliar. As atividades universitárias também foram impactadas, porém, a coordenadora do projeto permaneceu em contato com a bolsista pelo formato virtual para o alinhamento de expectativas. Após muito diálogo, ficou definido que 
Ações de promoção da saúde com a equipe do consultório na rua de Florianópolis

o projeto permaneceria em formato digital através da interação via mídias do grupo de pesquisa. Dessa forma, foi elaborado um cronograma semanal de postagens acerca da temática da PSR e políticas disponíveis pelo Ministério da Saúde, bem como foram elaborados vídeos para reforçar a temática. Essa atividade remota teve a intenção de produzir materiais informativos, fomentar a produção científica e divulgar o conteúdo a respeito do projeto.

\section{CONSIDERAÇÕES FINAIS}

A docência universitária exige a articulação entre ensino, pesquisa e extensão. Faz parte dessa característica integradora a produção do conhecimento bem como sua socialização. A indissociabilidade aponta para a atividade reflexiva e problematizadora do professor. Articula componentes curriculares e projetos de pesquisa e de intervenção, levando em conta que a realidade social não é objetivo de uma disciplina e isso exige o emprego de uma pluralidade metodológica. A pesquisa e a extensão indissociadas da docência necessitam interrogar o que se encontra fora do ângulo imediato de visão. O conhecimento científico produzido pela universidade não é para mera divulgação, mas é para a melhoria de sua capacidade de produção de saúde e vida.

O ensino como extensão aponta para a formação contextualizada às agudas questões da sociedade contemporânea e o ensino como pesquisa aponta para o verdadeiro domínio dos instrumentos nos quais cada profissão se expressa, em seu próprio processo evolutivo. O ensino permeado de ações de diálogo, onde o aluno é atuante e coparticipe do processo de aprendizagem, incentiva que o mesmo busque inserir-se em atividades na comunidade e nos serviços de saúde, tendo em vista a troca de saberes, a promoção da interdisciplinaridade e a democratização do conhecimento.

Uma característica da docência universitária é estar ligada à inovação no ensino, ou seja, estar sempre disposto a aprender, pesquisar e avaliar, sendo capaz de reconfigurar saberes, procurando superar as dicotomias entre conhecimento científico e senso comum, ciência e cultura, educação e trabalho, teoria e prática. Para que isto possa ser efetivado, faz-se necessário explorar novas alternativas teórico-metodológicas em busca de outras possibilidades de escolhas, bem como procurar uma renovação da sensibilidade ao alicerçar-se na dimensão ética e estética, no novo e no criativo, na inventividade coletiva.

Assim, esta oportunidade de atuar na formação de futuros enfermeiros implica em também compreender a importância do papel da docência, propiciando uma profundidade 
Ações de promoção da saúde com a equipe do consultório na rua de Florianópolis

científico-pedagógica que nos habilite a enfrentar questões fundamentais em uma prática social que ressaltem ideias de formação e reflexão crítica, sobre os sujeitos, sobre si mesmo e sobre o mundo.

\section{AGRADECIMENTOS:}

Aos componentes do grupo de pesquisa (Re)Habilitar da UFSC que desenvolveram ações presenciais ou à distância como apoiadores do projeto, em especial: Lucas, Caroline, Maitê, Kenny, Miriam, Ana e Daniella. Estendo os agradecimentos à eCR de Florianópolis.

\section{REFERÊNCIAS}

BRASIL, Ministério da Saúde do. Secretaria de Atenção à Saúde (org). Manual sobre o cuidado à saúde junto a população em situação de rua. Brasilia: Departamento de Atenção Básica, 2012. 98 p. (Série A. Normas e Manuais Técnicos).

GOMES, Rosilaine dos Santos; SOUZA, Marcia Romovicz da Silva; LOPES, Mirian Cristina. Enfrentamento das expressões da questão social nos diferentes equipamentos/instituições onde o serviço social atua com a população em situação de rua. Caderno Humanidades em Perspectivas, Curitiba, v. $7, \quad$ n. 3, p. 85-95, 2019. Disponível em: https://www.uninter.com/cadernosuninter/index.php/humanidades/article/view/937/1046.

Acesso em: 07 nov. 2020.

INSTITUTO DE PESQUISA ECONÔMICA APLICADA (IPEA) (Brasil) (org.). População em situação de rua cresce e fica mais exposta à Covid-19: maioria vive em grandes cidades do sudeste, nordeste e sul. Maioria vive em grandes cidades do Sudeste, Nordeste e Sul. 2020. Disponível em: https://www.ipea.gov.br/portal/index.php?option $=$ com_content\&view $=$ article\&id $=35811 \#: \sim: t$

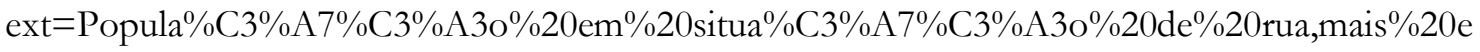
xposta $\% 20 \%$ C3 $\%$ A0 $\% 20$ Covid $\% 2$ D 19 \&text $=$ A $\% 20$ popula $\%$ C $3 \%$ A7 $\%$ C $3 \%$ A3o $\% 20$ em $\% 20$ situ a $\%$ C3 $\%$ A $7 \%$ C3 $\%$ A30 $\% 20$ de,pela $\% 20$ pandemia $\% 20 \mathrm{da} \% 20$ Covid $\% 2$ D 19 . Acesso em: 07 nov. 2020 .

MACHADO, Marcelo Pedra Martins; RABELLO, Elaine Teixeira. Competências para o trabalho nos Consultórios na Rua. Physis, Rio de Janeiro, v. 28, n. 4, p. 1-24, 2018. Disponível em http://www.scielo.br/scielo.php?script=sci_arttext\&pid=S0103-

$73312018000400610 \& \operatorname{lng}=$ en\&nrm $=$ iso. acesso em 07 de novembro de 2020. Acesso em: 07 nov. 2020. https://doi.org/10.1590/s0103-73312018280413.

MATOSO, Leonardo Magela Lopes et al. Redução de riscos e danos: Ações em saúde com pessoas em situação de rua no interior nordestino. Revista Contexto \& Saúde, Ijuí, v. 19, n. 37, p. 183-188, 17 dez. 2019. Editora Unijui. Disponível em: https://www.revistas.unijui.edu.br/index.php/contextoesaude/article/view/8109. Acesso em: 21 jul. 2020. Acesso em: 07 nov. 2020. http://dx.doi.org/10.21527/2176-7114.2019.37.183-188. 
Ações de promoção da saúde com a equipe do consultório na rua de Florianópolis

PRÓ REITORIA DE EXTENSÃO (Brasil). Universidade Federal de Santa Catarina (org.). Catálogo de extensão 2019. Florianópolis: PROEX/UFSC, 2019. 281 p. Disponível em: https://proex.paginas.ufsc.br/files/2019/10/Cat\%C3\%A1logo-de-Extens\%C3\%A3o-2019-

WEB.pdf. Acesso em: 27 out. 2020.

SILVA, Jainatan Rocha; PRADO, Érika Rosângela Alves; RODRIGUES, Nayra Monisy dos Santos. Promoção e educação em saúde: $\mathrm{O}$ empoderamento das pessoas em situação de rua na perspectiva do cuidado à saúde. Brazilian Journal of Development, Curitiba, v. 6, n. 3, p. 11608-11620, 2020. Disponível em: http://www.brazilianjournals.com/index.php/BRJD/article/view/7540. Acesso em: 12 jun. 2020. http://dx.doi.org/10.34117/bjdv6n3-139.

WIJK, Lívia Bustamante van; MANGIA, Elisabete Ferreira. Atenção psicossocial e o cuidado em saúde à população em situação de rua: uma revisão integrativa. Ciênc. saúde coletiva, Rio de Janeiro, v. 24, n. 9, p. 3357-3368, set. $2019 . \quad$ Disponível em http:/ /www.scielo.br/scielo.php?script=sci_arttext\&pid=S1413-

$81232019000903357 \& \operatorname{lng}=$ pt\&nrm=iso.

Acesso em: 07 nov. 2020. https://doi.org/10.1590/1413-81232018249.29872017.

ZANDOMINGO, Mayara Novais Pereira et al. Pobreza, fome e abandono: representações da equipe de enfermagem sobre pessoas em situação de rua. Rev. Bras. Enferm., Brasilia, v. 73, n. 1, p. 1-8, 2020. Disponível em: http://www.scielo.br/scielo.php?script=sci_arttext\&pid=S0034$71672020001300168 \& \operatorname{lng}=$ en\&nrm $=$ iso.

Acesso em: 07 Nov.2020. https://doi.org/10.1590/0034-7167-2019-0338.

Recebido em: 20/11/2019

Aceito em: $11 / 12 / 2020$ 